\title{
Correlation between urodynamic tests, history and clinical findings in treatment of women with urinary incontinence
}

\author{
Correlação entre o estudo urodinâmico, a anamnese e os achados clínicos na abordagem de \\ mulheres com incontinência urinária
}

João Bosco Ramos Borges ${ }^{1}$, Telma Guarisi², Ana Carolina Marchesini de Camargo ${ }^{3}$, Pítia Cárita de Godoy Borges ${ }^{4}$

\begin{abstract}
Objective: The aim of this study was to evaluate the role of urodynamic test in diagnosis of urinary incontinence, comparing detailed data of history and physical examination, and some easyto-apply clinical tests. Methods: A cross-sectional retrospective study was carried out by reviewing the medical charts of 55 patients with complaint of loss of urine, seen at the Urogynecology Service of Women's Health Outpatient Clinic of Hospital Universitário de Jundiaí, between October 2006 and March 2007. The patients answered a specific questionnaire involving the epidemiological and physical examination variables considered in this study. They were submitted to physical examination and urodynamic tests. Results: The complaint of loss of urine upon exertion, either isolated or associated with urge incontinence, was confirmed by urodynamic tests in most women, and only 4 of 49 symptomatic women had negative results. The clinical sign was present in 35 patients $(63.6 \%)$, and 46 patients $(83.6 \%)$ had the exertion component in the urodynamic test. The exertion component was observed in 10 $(18 \%)$ out of 15 patients without symptoms (30\%). The positive and negative predictive values of the clinical sign for diagnosis of any type of urinary incontinence in this studied group were 97.1 and $26.7 \%$, respectively. As for the clinical complaint of urinary loss upon exertion, the positive and negative predictive values for any type of urinary incontinence were 92 and $40 \%$, respectively. For the clinical complaint of urge incontinence, the positive and negative predictive values of 92.5 and $23.1 \%$, respectively. Conclusions: It was concluded that the urodynamic evaluation is an important instrument to evaluate the severity of incontinence, although it was not necessary to diagnose loss of urine. The finding of urinary loss during physical examination had low sensitivity and specificity in diagnosis of the type of loss of urine. Urodynamic tests had better performance in demonstrating urinary incontinence in patients with complaint of incontinence upon exertion and without loss
\end{abstract}

of urine seen upon physical examination than in confirming urge incontinence in patients with those symptoms.

Keywords: Urinary incontinence/diagnosis; Urodynamics; Medical history taking; Retrospective studies

\section{RESUMO}

Objetivo: 0 objetivo do presente estudo foi avaliar o papel do estudo urodinâmico no diagnóstico da incontinência urinária, comparando-se os dados de anamnese e exame físico detalhados, somados a alguns testes clínicos de fácil aplicação. Métodos: Foi realizado estudo retrospectivo de corte transversal, por meio da revisão de prontuário de 55 pacientes com queixa de perda urinária atendidas no Serviço de Uroginecologia do Ambulatório da Saúde da Mulher do Hospital Universitário de Jundiaí, no período de outubro de 2006 a março de 2007. Essas pacientes, durante sua consulta, responderam a um questionário específico, que contempla as variáveis epidemiológicas e de exame físico consideradas no estudo, tendo sido submetidas a exame físico e ao estudo urodinâmico. Resultados: A queixa de perda de urina aos esforços, isolada ou associada a urgeincontinência, foi confirmada pelo estudo urodinâmico na grande maioria das mulheres, sendo que 0 exame mostrou-se negativo em apenas 4 de 49 mulheres com queixa. 0 sinal clínico estava presente em 35 pacientes $(63,6 \%)$, sendo que $46(83,6 \%)$ apresentavam 0 componente de esforço no estudo urodinâmico. Entre as $15 \mathrm{com} 0$ sinal ausente $(30 \%)$, o componente de esforço foi observado em 10 (18\%). Os valores preditivos positivo e negativo do sinal clínico para o diagnóstico de algum tipo de incontinência urinária nesse grupo estudado foram de 97,1 e $26,7 \%$, respectivamente. Em relação à queixa clínica de perda de urina aos esforços, os valores preditivos positivo e negativo para algum tipo de incontinência urinária foram de 92 e 40\%, respectivamente. Quanto à queixa clínica de urge-

\footnotetext{
Study carried out at Faculdade de Medicina de Jundiaí - FMJ, Jundiaí (SP) Brazil.

This study received a grant from the PIBIC-CNPq.

${ }^{1}$ Full Professor of Gynecology of Faculdade de Medicina de Jundiaí - FMU, Jundiaí (SP), Brazil.

${ }^{2} \mathrm{PhD}$ at Universidade Estadual de Campinas - UNICAMP, Campinas (SP), Brazil.

${ }^{3}$ Master degree; Assistant professor of Ginecology of Faculdade de Medicina de Jundiaí - FMJ, Jundiaí (SP), Brazil.

${ }^{4}$ Master degree; Assistant professor (temporary) of Ginecology of Faculdade de Medicina de Jundiaí - FMJ, Jundiaí (SP), Brazil.

Corresponding author: João Bosco Ramos Borges - Rua Francisco Telles, 250 - Vila Arens - CEP 13202-550 - Jundiaí (SP), Brasil - Tel.: 4587-1095 - E-mail: drbosco@terra.com.br

Received: Jan 24, 2010 - Accepted: Jun 09, 2010
} 
incontinência, observaram-se valores preditivos positivo e negativo de 92,5 e $23,1 \%$, respectivamente. Conclusões: Concluiu-se que a avaliação urodinâmica representa importante instrumento para avaliar o grau da incontinência, porém não se mostrou necessária para o diagnóstico da perda urinária. 0 achado de perda durante 0 exame físico tem baixa sensibilidade e especificidade no diagnóstico do tipo de perda urinária. A urodinâmica teve melhor desempenho em demonstrar a incontinência urinária em pacientes com queixa de incontinência urinária aos esforços, porém sem perda de urina visualizada no exame físico, em relação à confirmação da urgeincontinência em pacientes com tais sintomas.

Descritores: Incontinência urinária/diagnóstico; Urodinâmica; Anamnese; Estudos retrospectivos

\section{INTRODUCTION}

Urinary incontinence (UI) is defined as any clinically proven involuntary loss of urine which causes a social or hygienic problem ${ }^{(1)}$. This symptom has social implications, causing discomfort and loss of self-esteem, negatively impacting the quality of life of many women.

It is a change that affects approximately one third of women of all ages. It is very likely an undernotified disorder and one of the reasons for this is that many UI patients do not spontaneously report this problem, unless when probed by physicians ${ }^{(2)}$.

The most frequent cause of UI is stress urinary incontinence (SUI) ${ }^{(3)}$, which is translated as a symptom, a sign and a condition. The symptom is the manifestation of involuntary loss of urine during physical exertion; the sign is represented by observation of urinary loss through the urethra due to increased intra-abdominal pressure, and the condition is associated to the loss of urine when the intravesical pressure becomes higher than the maximum urethral pressure in the absence of contractile activity of the detrusor muscle ${ }^{(3)}$. Thus, the concept of SUI is based on clinical and urodynamic data. The second most common cause of UI among women stems from hyperactivity of the detrusor muscle (hyperactive bladder).

The prevalence of UI in the different studies varies broadly, with reports ranging from 17 to $45 \%$ of adult women $^{(4-5)}$. One of the hypotheses used to explain the broad variation in these studies would be the type of population studied, the definition of UI used and the patient selection criteria.

Another point for discussion is associated with the diagnosis of different forms of UI, more specifically the need to do an urodynamic test in the initial evaluation of a patient with UI complaints. Many specialists initially use the characteristics of the symptoms to make diagnosis and often times even to start the treatment of SUI and urge incontinence. Others recommend the routine evaluation through urodynamics. Clinical studies have considered both practices, some showing that the symptoms reported in the clinical history are sensitive and specific in the diagnosis of different types of UI, while others say that the clinical data are not sensitive, nor specific ${ }^{(6)}$.

Urodynamics has been broadly used in the diagnostic and prognostic evaluation of UI, nonetheless there is no consensus as to its real need. Some authors believe it is not necessary at the initial assessment of patients with UI because of its high cost and variable tolerability among patients, who often times say they do not want to be submitted to it again ${ }^{(7,8)}$. Others believe that the test is useful for women with lower urinary tract symptoms, besides helping to improve knowledge and providing a more accurate diagnosis, leading to a more effective treatment, therefore being truly necessary despite its high financial $\operatorname{cost}^{(9,10)}$.

A variable number of incontinent patients may have normal urodynamics, despite the high sensitivity of the test, especially concerning the diagnosis of SUI ${ }^{(11)}$. Sometimes there is no correlation between urinary symptoms and urodynamic test findings, and the subjective complaints are not enough to differentiate the UI etiology ${ }^{(12)}$.

SUI must be confirmed by a positive history, by a clinical-gynecological examination in which urethral hypermobility can be observed and with a positive cough test, thus saving urodynamic evaluation for those women with mixed urinary incontinence (MUI) ${ }^{(13)}$. There is evidence that in women with MUI there is a higher incidence of detrusor instability when compared to those with pure SUI symptoms ${ }^{(14)}$.

Duggan et al. evaluated the behavior of specialists and general practitioners concerning their referral of patients to an urodynamic evaluation in the preoperative assessment of women with SUI, and most of them favored the test ${ }^{(15)}$. In cases of non-complicated SUI, most specialists and some general practitioners use cystometry, saving uroflowmetry for the most severe cases. The general practitioners do not order the test for it is difficult to interpret, and because it may not be available near their office. Among the specialists, it is more associated with lack of reliability on the test concerning a detailed clinical history and data from a careful physical examination. Hence, not everyone orders it, even in more complex cases.

In our settings, Kawano et al. suggest, after preliminary observations, that the urogynecological workup associated to simplified cystometry is an option to be considered in the clinical and preoperative assessment of patients with SUI, replacing conventional urodynamics, especially where the latter is not available ${ }^{(16)}$. They also concluded that simplified cystometry is an accessible test that is able to detect involuntary contractions of the detrusor muscle, 
as well as to identify urinary loss with relative sensitivity, providing the examiner with reliable information concerning bladder behavior.

Urodynamic parameters do not seem proper to assess treatment impact on the quality of life of patients. After treatment, some clinical methods, such as questions concerning severity of the UI and the quantity of urinary loss in the absorbent pad test within 48 hours, proved to be more reliable ${ }^{(17)}$. Thus, there are divergences as to the indication and the real need of routine urodynamic evaluation in the investigation of UI in women. In our country, it plays a relevant role, considering the high cost and the few clinics that have the test available to study such a frequent complaint like UI in women.

\section{OBJECTIVE}

To assess the role of urodynamics in the diagnosis of UI, comparing the data from detailed history and physical examination, added to some clinical tests that are easy to employ.

\section{METHODS}

After approval by the Research Ethics Committee, a cross-sectional retrospective study was conducted by reviewing the charts from 55 patients complaining of urinary loss, who were seen at the Urogynechology Service of Women's Health Outpatient Clinic of Hospital Universitário de Jundiaí, from October 2006 to March 2007. These patients answered a specific questionnaire approaching epidemiological and physical examination variables considered in the study, and the issues concerning urinary complaints included those of the Norwegian EPINCONT Study ${ }^{(18)}$.

The population variables considered in this study were: age in complete years; ethnicity (Caucasian, black, mulatto, indigenous or oriental); marital status (married, single, divorced, separated, widower or living together); parity (number of deliveries); type of delivery (vaginal, forceps, C-section without labor or C-section with labor); schooling (illiteracy, primary education, secondary education, university education).

The issues associated with urinary complaints included those of the Norwegian EPINCONT Study ${ }^{(18)}$, shown in Table 1 . The data from the physical examination were considered after inspecting the external genitalia to characterize and classify the degree of genital dystopia, as follows:

a)prolapse of the anterior vaginal wall, which was classified as absent; first degree, when it does not reach the vaginal introitus during stress; second degree, when it reaches the vaginal introitus during stress; third degree, when it trespasses the vaginal introitus upon stress and fourth degree, when it trespasses the vaginal vestibule upon rest;

b)prolapse of the posterior vaginal wall, classified as grade 1 , when it does not affect the vaginal introitus upon stress (mild); degree 2, when it reaches the vaginal introitus upon stress (moderate) and degree 3 , when it trespasses the vaginal introitus upon stress (severe).

Moreover, during the physical examination, the clinical test called "stress test" was performed, in which loss of urine can be objectively demonstrated or not, simultaneous with physical exertion, with the patient with a full bladder in lithotomy and orthostatic positions. Moreover, the quantity of urine voided during stress is classified into small, medium and large.

In the urodynamic evaluation, the following aspects were considered: the presence or not of contractions that were not inhibited by the detrusor; presence or not of urinary loss; and the Valsalva leak point pressure (VLPP) measured in $\mathrm{cmH}_{2} \mathrm{O}$. The final diagnosis of the urodynamic test is subdivided into SUI (broken

Table 1. Characterization of urinary complaints of the studied patients

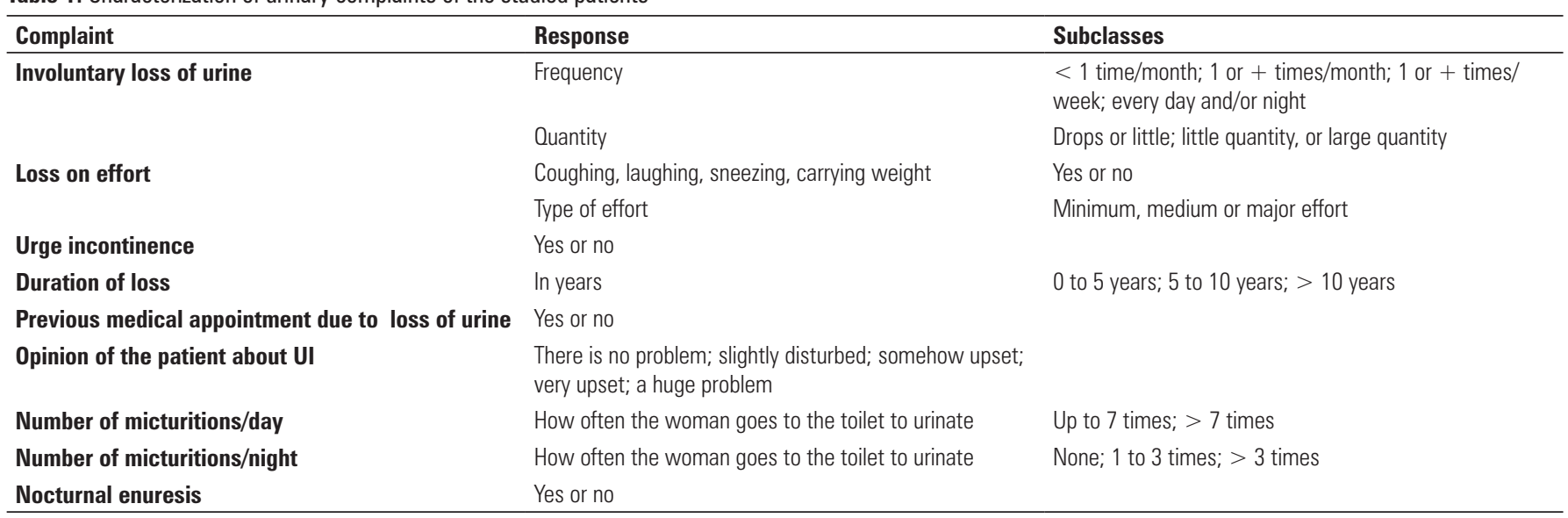


down into type I: VLPP > $110 \mathrm{cmH}_{2} \mathrm{O}$; type II: VLPP between 60 and $110 \mathrm{cmH}_{2} \mathrm{O}$ and type III: VLPP $<60$ $\mathrm{cm} \mathrm{H}_{2} \mathrm{O}$ ); detrusor hyperactivity $(\mathrm{DH})$ : when the test showed uninhibited detrusor contractions; and MUI when there was diagnosis of concurrent DH and SUI.

\section{Data analysis}

The distribution of variable was initially analyzed using descriptive tables. In order to check the statistical significance, the $X^{2}$ test, Fisher's exact test, sensitivity, specificity, positive and negative predictive values were considered.

\section{RESULTS}

The mean age was $55.4 \pm 11.6$ years; most were Caucasians $(76 \%)$ and a little more than half of them had incomplete primary education $(65 \%)$. Among the studied women, $53 \%$ were postmenopausal, with a mean of 4.4 pregnancies and a predominance of vaginal deliveries (3.7 vaginal deliveries/woman).

Of the 55 women, most $(47.3 \%)$ had associated symptoms of urge incontinence and stress incontinence. Eleven patients $(20 \%)$ complained only of stress urinary incontinence, and 4 (7.3\%) reported only urge incontinence. Nocturnal enuresis and nocturia were also reported (Table 2).

For about $60 \%$ of the women, UI was a severe problem and about $25 \%$ were very upset, regardless of the type of UI. Nonetheless, only $60.4 \%$ of them had a previous appointment for this complaint. As far as physical exam is concerned, most patients had $1^{\text {st }}$ or $2^{\text {nd }}$ degree cystocele and mild to moderate rectocele.

Upon analysis of the urodynamic evaluation results, approximately $11 \%$ of the patients had a normal test. $\mathrm{DH}$ alone was confirmed by the urodynamic study in three patients only. Most of the patients (69\%) had urodynamic tests matching parameters for SUI. Among those, 9 had loss of urine with VLPP $>110 \mathrm{cmH}_{2} \mathrm{O}, 13$ had VLPP between 60 and $110 \mathrm{cmH}_{2} \mathrm{O}$, and 16 had loss of urine with pressure below $60 \mathrm{cmH}_{2} \mathrm{O}$ (Table 2).

Table 2. Distribution of patients per type of urinary complaint, physical examination finding and result of urodynamic evaluation $(n=55)$

\begin{tabular}{llcc}
\hline Variables & & $\mathbf{n}$ & $\%$ \\
\hline Urinary complaint & & 13 & 24.5 \\
Nocturia & & 17 & 31.5 \\
Nocturnal enuresis & & 12 & 21.8 \\
SUI alone & 3 & 5.4 \\
Urge incontinence alone & & 37 & 67.2 \\
Mixed UI & & & \\
\hline Genital dystopia & Absent & 12 & 22.6 \\
Cystocele & $1^{\text {st }}$ degree & 18 & 34.0 \\
& $2^{\text {nd }}$ degree & 17 & 32.1 \\
& $3^{\text {rd }}$ degree & 6 & 11.3 \\
Rectocele & Absent & 11 & 21.2 \\
& Mild & 26 & 50.0 \\
& Moderate & 12 & 23.0 \\
& Severe & 3 & 5.8 \\
\hline Urodynamic evaluation & & & \\
Normal & & 6 & 10.9 \\
Detrusor hyperactivity & & 3 & 5.5 \\
Type I SUl & & 9 & 16.4 \\
Type II SUI & & 13 & 23.6 \\
Type III SUI & & & 29.1 \\
Mixed UI & & 14.5 \\
\hline
\end{tabular}

Of all the studied women, more than half $(\mathrm{n}=$ 30) complained of loss of urine upon minimum stress; nonetheless, upon urodynamic investigation, only 18 (32.7\%) had VLPP below $60 \mathrm{cmH}_{2} \mathrm{O}$.

The prevalence of clinical urogynecological complaints and their correlation with the final urodynamic diagnosis can be seen on Table 3. Loss upon stress as a single complaint was seen in 12 women $(21.8 \%)$, and 2 of them had unstable bladder. Only three patients complained of urgency/urge incontinence

Table 3. Prevalence of urogynecological complaints and their correlation with urodynamic findings

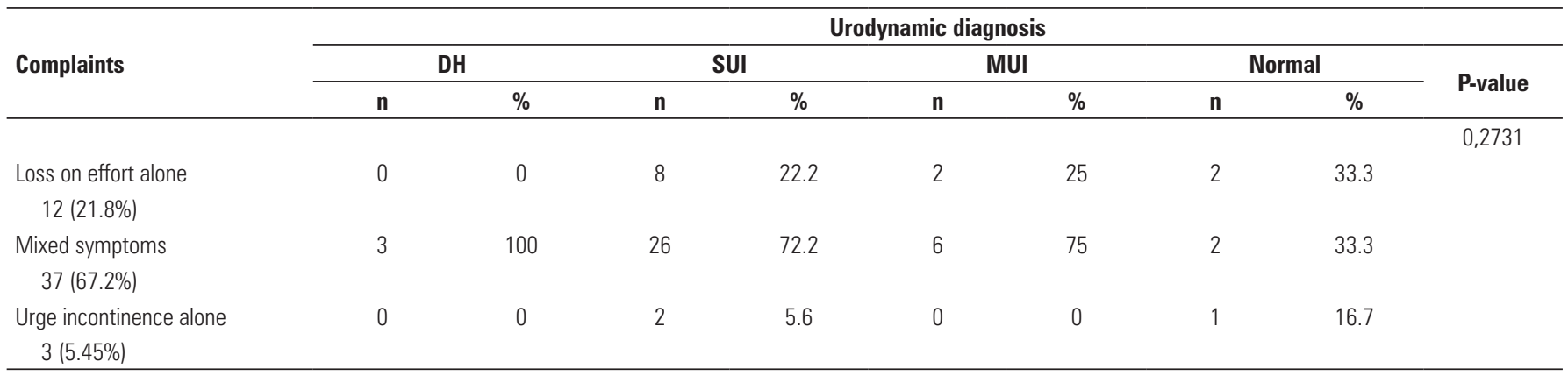

$\mathrm{DH}$ : detrusor hyperactivity; SUI: stress urinary incontinence; MUI: mixed urinary incontinence.

Fisher exact test. 
Table 4. Correlation between clinical complaint of loss of urine on effort, urge incontinence, clinical finding of loss of urine and urodynamics diagnosis

\begin{tabular}{|c|c|c|c|c|c|c|}
\hline \multirow{2}{*}{ Parameter } & & \multicolumn{5}{|c|}{ Urodynamics diagnosis } \\
\hline & & SUI & MUI & DH & Normal & Total \\
\hline \multirow[t]{2}{*}{ Loss of urine on effort } & Present & 35 & 8 & 3 & 4 & 50 \\
\hline & Absent & 3 & 0 & 0 & 2 & 5 \\
\hline \multirow[t]{2}{*}{ Urge incontinence } & Present & 28 & 6 & 3 & 3 & 40 \\
\hline & Absent & 8 & 2 & 0 & 3 & 13 \\
\hline Clinical sign of loss of urine & Present & 27 & 6 & 1 & 1 & 35 \\
\hline
\end{tabular}

Table 5. Performance of urodynamics diagnosis regarding complaint of loss of urine on effort, complaint of urge incontinence and clinical finding of loss of urine

\begin{tabular}{lcccc}
\hline \multirow{2}{*}{ Parameter } & \multicolumn{3}{c}{ Urodynamics diagnosis } \\
\cline { 2 - 5 } & Sensibility (\%) & Specificity (\%) & PPV (\%) & NPV (\%) \\
\hline Loss of urine on effort & 93.9 & 33.3 & 92 & 40 \\
Urge incontinence & 78.7 & 50 & 92.5 & 23.1 \\
Clinical sign of loss of urine & 75.6 & 80 & 97.1 & 26.7 \\
\hline
\end{tabular}

PPV: Positive predictive value; NPV: Negative predictive value.

alone and none of them had unstable bladder upon the urodynamic study. Thirty-seven $(67.2 \%)$ patients had mixed symptoms, making up for most of the population investigated. However, the presence of uninhibited contractions, characterizing DH, was seen in only 9 patients.

The complaint of loss of urine upon stress, alone or associated with urge incontinence, was confirmed by the urodynamic study in most women, and only 4 among 49 women with the complaint had a negative test (Table 4).

The correlation between the clinical sign of loss of urine and the urodynamic study is depicted on Table 4. The clinical sign was present in 35 patients $(63.6 \%)$, and $46(83.6 \%)$ had the stress component shown in the urodynamic test. Among the 15 women with absent sign $(30 \%)$, the stress component was seen in $10(18 \%)$. The positive and negative predictive values of the clinical sign for diagnosis of some type of UI in this studied group were 97.1 and $26.7 \%$, respectively.

In regards of the clinical complaint of loss of urine upon stress, the positive and negative predictive values for some type of UI were of 92 and $40 \%$, respectively (Table 5). As to the clinical complaint of urge incontinence, the positive and negative predictive values were 92.5 and $23.1 \%$, respectively (Table 5).

\section{DISCUSSION}

The inadequate assessment and the incorrect diagnosis of the UI etiology have multiple consequences, and the most severe is the indication of inapropriate or unnecessary surgeries. Successive surgical procedures have progressive lower rates of success, besides a greater surgical risk and higher postoperative complication rates. It is widely accepted that the best anti-incontinence procedure as far as success is concerned is the correct evaluation $^{(19)}$.

The data from the present investigation must be carefully interpreted because it is a retrospective analysis of a selective group of women with UI from a specialized hospital service. However, the findings have implications for the diagnostic assessment of women with complaints of UI and must be followed up by further studies.

The findings of this study, similarly to those reported in the literature ${ }^{(20)}$, indicated that the presence of incontinence symptoms among women is highly predictive of abnormalities found in the urodynamic study. Nonetheless, they also allow us to consider highly important the detailed clinical approach, which can lead to diagnosis in most patients.

Among urinary symptoms, the most frequent was MUI, reported by most patients, while a lower number had only SUI; and only a minimum number reported urge incontinence alone. These results are almost identical to those reported by Ouslander et al. ${ }^{(20)}$. In general, the literature shows that SUI is the first cause of UI in women, followed by urge incontinence; however, when women are assessed during premenopause, urge incontinence due to detrusor hyperactivity becomes the first cause and SUI ranks second. These facts corroborate our findings once again, since in the present study the mean age of women depicted the period corresponding to transition from reproductive life to postmenopause.

In the population of this study, the rate of women with urinary incontinence who visited a physician was identical to that described by Stemberg ${ }^{(21)}$ among menopausal women, and by Guarisi (22), among premenopausal women. Concerning those who sought medical care because of UI, less than half of the women 
who participated in the study had not been through any prior consultation for such reason. These findings coincide with other reports in the literature, in which 21.3 to $27 \%$ of women visited physicians on account of their UI ${ }^{(5,23,24)}$. Considering the impact on quality of life that such problem can cause, most women in the present study considered loss of urine as a severe problem or felt very upset because of it, differently from the results reported by Hannestad et al., in which most women with incontinence reported it as a mild problem ${ }^{(18)}$.

The goal of urodynamic evaluation is to identify the specific causes of symptoms reported by patients, namely UI, urinary dysfunction or irritative symptoms of the urinary tract ${ }^{(25)}$, besides providing data to guide proper treatment, either surgical or not. The final diagnosis is the result of a continuous interaction between patients and examiners, and data interpretation and information concerning artifacts are of great importance ${ }^{(26)}$.

The clinical complaint most often reported among the subjects of this study was MUI, but the most frequent urodynamic finding was SUI, distributed in a growing fashion into types I, II and III. Only half of the women with clinical complaint of urinary loss upon minimum stress had loss pressure values below $60 \mathrm{cmH}_{2} \mathrm{O}$, showing that for this type of clinical complaint the urodynamic study is important so as not to overestimate the degree of incontinence, which could lead to a less conservative treatment. If only urinary loss upon stress is considered, regardless of the type of stress, a positive correlation between clinical findings and urodynamics is observed.

Some studies showed that one in every nine women can be unnecessarily operated on when the diagnosis was based only on data from the history and on the results from the Q-tip-test; hence, the treatment will be empirical and the surgical success will be low.

It must be born in mind that the clinical quantification of urinary loss is subjective, while based on information given by the patient. Studies from the 1980's had already concluded that the clinical proof of stress urinary loss was present in only $41 \%$ of the cases with final diagnosis of pure or mixed SUI. Moreover, 32\% of patients with such sign had another diagnosis besides SUI ${ }^{(26)}$.

Such observations were confirmed when assessing the efficacy of the clinical sign of urinary loss upon stress as compared to the urodynamic study in 863 patients. It was concluded that the sign is present in only $54.2 \%$ of 574 women with a final diagnosis of SUI ${ }^{(27)}$. Moreover, $38 \%$ had another additional diagnosis, such as bladder instability. It was observed that the clinical sign had a positive predictive value of $91 \%$ and a negative predictive value of $50 \%$. In our country, Feldner et al. found positive and negative predictive values of 82 and $53.1 \%$, respectively, for clinical sign in the diagnosis of SUI ${ }^{(28)}$.
Despite the high positive predictive values found in these studies, there were no elements indicating the possibility of differentiating SUI due to sphincter defect, which would be important in the choice of surgical treatment. In the current study, the clinical sign of urinary loss upon stress was present in $63.6 \%$ of the patients, and $83.6 \%$ had the stress component in the urodynamic study. Among the 15 women without such sign, the stress component was seen in 10 . The positive and negative predictive values of the clinical sign for the diagnosis of some type of UI in this studied group were 97.1 and $26.7 \%$, respectively.

Based upon the results from this study, one verifies that if patients had been treated with no urodynamic tests, at least $16 \%$ of them would not be clinically treated, for presenting type I SUI and, on the other hand, almost one third of the patients, who had type III SUI, could have received inadequate surgical treatment, considering that this type of incontinence requires specific treatment, that is the sling surgery.

DH associated with SUI is an important risk factor in predicting treatment success, and clinical treatment should be proposed prior to surgery for this group of patients. Micturition changes also represent relevant findings, since these women have a higher risk of developing urinary retention in the postoperative period $^{(27)}$. Concerning the clinical complaint of urge incontinence, on the contrary, the urodynamic study did not show a significant role, since most patients with this symptom did not have involuntary contractions of the detrusor muscle during the exam, which is supported by the change in nomenclature and diagnostic criteria for hyperactive bladder syndrome based on the International Continence Society (ICS) consensus ${ }^{(1)}$, which considers the diagnosis of hyperactive bladder as the presence of urgency symptoms and increased urinary frequency with no need to find involuntary contractions of the detrusor muscle during urodynamic evaluation.

These data indicate the importance of clinical evaluation, which should not be replaced by the urodynamic test that is many times attributed greater relevance. Undoubtedly, the urodynamic findings contribute to diagnosis of the type of loss, but cannot represent the "gold standard" method; otherwise a large number of patients with this problem, especially urge incontinence, will not be treated.

A detailed history appreciating the type of complaint, backed up by some clinical findings, can already guide the initial treatment and spare some women of the urodynamic test. This happens because the urodynamic tests are invasive when compared to clinical assessment, may yield different results according to different test modalities and it is not possible to correlate the results from these urodynamic tests with the effects 
of non-invasive treatment. Thus, such tests are not recommended in the initial evaluation in order to start conservative treatment ${ }^{(28)}$.

\section{CONCLUSIONS}

With such findings at hand, it was concluded that the urodynamic evaluation represents an important tool to assess the degree of incontinence; however, it did not prove necessary for the diagnosis of urinary loss. The finding of urinary loss during physical examination has low sensitivity and specificity in diagnosis of the type of urinary loss. Urodynamic tests had best performance in showing UI in patients complaining of SUI (however with no urinary loss seen upon physical examination) when compared to the confirmation of urge incontinence in patients with such symptoms.

Further studies are necessary in order to confirm the results obtained in the present investigation, as well as to find more detailed data, especially concerning physical examination and other clinical tests, enabling us to continue improving and appreciating the clinical approach of women with UI.

\section{REFERENCES}

1. Abrams P, Artibani W, Cardozo L, Dmochowski R, van Kerrebroeck P, Sand P; International Continence Society. Reviewing the ICS 2002 terminology report: the ongoing debate. Neurourol Urodyn. 2009;28(4):287.

2. Guarisi T, Pinto-Neto AM, Osis MJ, Pedro AO, Costa-Paiva LHS, Faúndes A. Procura de serviço médico por mulheres com incontinência urinária. Rev Bras Ginecol Obstet. 2001;23(7):439-43.

3. Long RM, Giri SK, Flood HD. Current concepts in female stress urinary incontinence. Surgeon. 2008;6(6):366-72.

4. Wallner LP, Porten S, Meenan RT, O'Keefe Rosetti MC, Calhoun EA, Sarma AV, et al. Prevalence and severity of undiagnosed urinary incontinence in women. Am J Med. 2009;122(11):1037-42.

5. Zhu L, Lang J, Liu C, Han S, Huang J, Li X. The epidemiological study of women with urinary incontinence and risk factors for stress urinary incontinence in China. Menopause. 2009;16(4):831-6.

6. Fantl JA, Newman DK, Colling J, DeLancey JO, Keeys C, Loughery R, et al. Urinary incontinence in adults guideline panel. In: The Agency for Health Care Policy and Research.Urinary incontinence in adults: acute and chronic management. Rockville (MD): AHCPR; 1996. [Clinical Practice Guideline, 2; AHCPR Publication, 96-0682].

7. Pushkar Dlu, Loran OB, Gumin LM, D'iakin W. [The diagnostic value of combined urodynamic study in different forms of urinary incontinence in women]. Urol Nefrol (Mosk). 1996;(4):21-5. Russian.

8. Teba del Pino F, Vírseda Chamorro M, Salinas Casado J, Arredondo Martínez F, Fernández Lao A, Fernández Lucas C. Female urinary incontinence: clinicalurodynamic correlation. Arch Esp Urol. 1999;52(3):237-42.

9. van Leijsen SA, Kluivers KB, Mol BW, Broekhuis SR, Milani FL, van der Vaart $\mathrm{CH}$, et al. Protocol for the value of urodynamics prior to stress incontinence surgery (VUSIS) study: a multicenter randomized controlled trial to assess the cost effectiveness of urodynamics in women with symptoms of stress urinary incontinence in whom surgical treatment is considered. BMC Womens Health. 2009;9:22.
10. Digesu GA, Athanasiou S, Chaliha C, Michalas S, Salvatore S, Selvaggi L, et al. Urethral retro-resistance pressure and urodynamic diagnoses in women with lower urinary tract symptoms. BJOG. 2006;113(1):34-8.

11. Colli E, Artibani W, Goka J, Parazzini F, Wein AJ. Are urodynamic tests useful tools for the initial conservative management of non-neurogenic urinary incontinence? A review of the literature. Eur Urol. 2003;43(1):63-9.

12. Lin HH, Torng PL, Sheu BC, Shau WY, Huang SC. Urodynamically age-specific prevalence of urinary incontinence in women with urinary symptoms. Neurourol Urodyn. 2003;22(1):29-32.

13. Laurikainen $E$, Killholma P. The tension-free vaginal tape procedure for female urinary incontinence without preoperative urodynamic evaluation. J Am Coll Surg. 2003;196(4):579-83.

14. Bump RC, Norton PA, Zinner NR, Yalcin I; Duloxetine Urinary Incontinence Study Group. Mixed urinary incontinence symptoms: urodynamic findings, incontinence severity, and treatment response. Obstet Gynecol. 2003;102(1):76-83.

15. Duggan PM, Wilson PD, Norton P, Brown AD, Drutz HP, Herbison P. Utilization of preoperative urodynamic investigations by gynecologists who frequently operate for female urinary incontinence. Int Urogynecol J Pelvic Floor Dysfunct. 2003;14(4):282-7.

16. Kawano PR, Amaro JL, Silva FS, Agostinho AD, Yamamoto HA, Trindade JCS. Urodinâmica convencional versus cistometria simplificada para caracterização da incontinência urinária feminina. Rev Bras Ginecol Obstet. 2004;26(4):311-6.

17. Stach-Lempinen B, Kirkinen P, Laippala P, Metsänoja R, Kujansuu E. Do objective urodynamic or clinical findings determine impact of urinary incontinence or its treatment on quality of life? Urology. 2004;63(1):67-71.

18. Hannestad YS, Rortveit G, Sandvik H, Hunskaar S; Norwegian EPINCONT study. Epidemiology of Incontinence in the County of Nord-Trøndelag. A community-based epidemiological survey of female urinary incontinence: the Norwegian EPINCONT study. Epidemiology of Incontinence in the County of Nord-Trøndelag. J Clin Epidemiol. 2000;53(11):1150-7.

19. Jensen JK, Nielsen FR Jr, Ostergard DR. The role of patient history in the diagnosis of urinary incontinence. Obstet Gynecol. 1994;83(5 Pt 2): 904-10.

20. Ouslander J, Staskin D, Raz S, Su HL, Hepps K. Clinical versus urodynamic diagnosis in an incontinent geriatric female population. J Urol. 1987;137(1):6871.

21. Stenberg A, Heimer G, Holmberg L, Ulmsten U. Prevalence of postmenopausal symptoms in two age groups of elderly women in relation to oestrogen replacement therapy. Maturitas. 1999;33(3):229-37.

22. Guarisi T, Pinto-Neto AM, Costa-Paiva LH, Pedro A0, Faúndes A. Fatores associados à prevalência de sintomas urinários em mulheres climatéricas. Rev Bras Ginecol Obstet. 1997;19:589-96.

23. Ushiroyama T, Ikeda A, Ueki M. Prevalence, incidence, and awareness in the treatment of menopausal urinary incontinence. Maturitas. 1999;33(2):12732.

24. Jensen JK. Urodynamic evaluation. In: Ostergard DR, Bent AE, editors. Urogynecology and urodynamics: theory and practice. $3^{\text {rd }}$ ed. Baltimore: Williams \& Wilkins; 1996. p. 115-49.

25. Wall LL, Norton PA. Practical urodynamics. In: Wall LL, Norton PA, editors. Practical urogynecology. Baltimore: Willians \& Wilkins; 1993. p. 83-124.

26. Haylen BT, Sutherst JR, Frazer MI. Is the investigation of most stress incontinence really necessary? Br J Urol. 1989;64(2):147-9.

27. Carey MP, Dwyer PL, Glenning PP. The sign of stress incontinence--should we believe what we see? Aust N Z J Obstet Gynaecol. 1997;37(4): 436-9.

28. Feldner Junior PC, Sartori MGF, Lima GR, Baracat EC, Girão MJBC. Diagnóstico clínico e subsidiário da incontinência urinária. Rev Bras Ginecol Obstet. 2006; 28(1):54-62. 